\title{
Extended meshless moving Kriging method for crack propagation analyzing in orthotropic media
}

\author{
Nguyen Thanh Nha, Nguyen Ngoc Minh, Bui Quoc Tinh, Truong Tich Thien*
}

\begin{abstract}
-orthotropic composite material is the particular type of anisotropic materials and their products have been extensively used in a wide range of engineering applications. Study on mechanical behaviors of such materials under working conditions is very essential. In this study, an extended meshfree moving Kriging interpolation method (namely as $\mathrm{X}$ MK) is presented for crack analyzing in 2D orthotropic materials models. The Gaussian function is used for constructing the moving Kriging shape functions. Typical advantages of the MK shape function are the high-order continuity and the satisfaction of the Kronecker's delta property. To calculate the stress intensity factors (SIFs), interaction integral method is used with orthotropic auxiliary fields. Several numerical tests including static SIFs calculating and crack propagation predicting are performed to verify the accuracy of the present approach. The obtained results are compared with available refered results and they have shown a very good performance of the present method.
\end{abstract}

Index Terms - orthotropic, crack, stress intensity factors, meshless, MK.

Received: 12-6-2017, Accepted: 18-11- 2017.

This research is funded by Ho Chi Minh city University of Technology, VNU-HCM, under grant number T-KHUD-201672. We thank our colleagues from Department of Engineering Mechanics who provided idea and expertise that assisted the study.

Nguyen Thanh Nha, Nguyen Ngoc Minh, Truong Tich Thien. Department of Engineering Mechanics, Faculty of Applied Sciences, Ho Chi Minh city University of Technology, VNUHCM. Email: tttruong@hcmut.edu.vn

Bui Quoc Tinh, Department of Civil and Environmental Engineering, Tokyo Insitute of Technology, 2-12-1-W8-22, Ookayama, Meguro-ku, Tokyo 152-8552, Japan.

\section{INTRODUCTION}

$\mathrm{I}$ n recent decades, orthotropic composite materials are used widely in various fields in engineering such as automobile, aerospace and civil industries, etc. One of the most advance property of composite is the strength per weight ratio of these materials is higher than other conventional engineering materials. In many cases, orthotropic composites are fabricated in thin plate or thin shell forms which are so easy to fault. Moreover, fiber enforced composites are so brittle and usually have linear elastic crack behavior without or with very little plasticity. For that reason, linear elastic crack behavior of orthotropic materials has become a very attracting study topic.

There are some important analytical solutions for othortropic crack models early given by Sih et al [1], Bowie et al [2], Tupholme et al [3], Barnet et al [4] and Kuo and Bogy [5]. They found out the singular fields such as displacement and stress near crack tip zone in anisotropic models. More recent contributions can be listed in Nobile et al $[6,7]$ and Carloni et al [8, 9]. However, analytical formulations cannot be applied to practical problems that have complex geometries and loading conditions. In the numerical fields, the extended finite element method (XFEM) has shown a very good capability in analyzing of fracture behavior of orthotropic materials, some typical publications can be listed in [10-14]. In XFEM, the finite element approximation is enriched with Heaviside function for crack face and appropriate functions extracted from the analytical solutions for a crack tip near field. Moreover, the element free Galerkin method (EFG) [15] has been applied for fracture analysis of 
composite by Ghorashi et al [16]. In this aproach, the support domain is modified to involve the discontinuity at the crack face and the singularity at the crack tip. Unlike the FEM, meshfree method uses a set of scattered nodes to model the domain and approximate the field variables. Because no finite element or mesh is required in the approximation, meshfree methods are very suitable for modeling crack growth problems [17-20].

In this work, an extended meshfree Galerkin method based on the moving Kriging interpolation method (X-MK) associated with the vector level set method is presented for modeling the crack problem in orthotropic materials. To calculate the SIFs, the interaction integral formulation for orthotropic materials is taken. Several numerical examples including static SIFs calculation and crack propagation angle prediction are performed and the obtained results are compared to the solutions given by other methods to verify the accuracy of the proposed method.

\section{FRACTURE MECHANICS FOR ORTHOTROPIC MATERIALS}

\subsection{Linear elastic behavior of orthotropic material}

In orthotropic material, the linear elastic stressstrain relations can be written as

$$
\boldsymbol{\varepsilon}=\mathbf{C \sigma}
$$

Where $\boldsymbol{\sigma}, \boldsymbol{\varepsilon}$ are linear stress and strain vectors, respectivily and $\mathbf{C}$ is the fourth-order compliance tensor. For plane stress problem, $\mathbf{C}$ can be defined as:

$$
\mathbf{C}^{2 D}=\left[\begin{array}{ccc}
1 / E_{1} & -v_{21} / E_{2} & 0 \\
-v_{12} / E_{1} & 1 / E_{2} & 0 \\
0 & 0 & 1 / G_{12}
\end{array}\right]
$$

Where $E_{1}, E_{2}, G_{12}$ and $v_{12}, v_{21}$ are Young's moduli, shear modulus and Poisson's ratios, respectively.

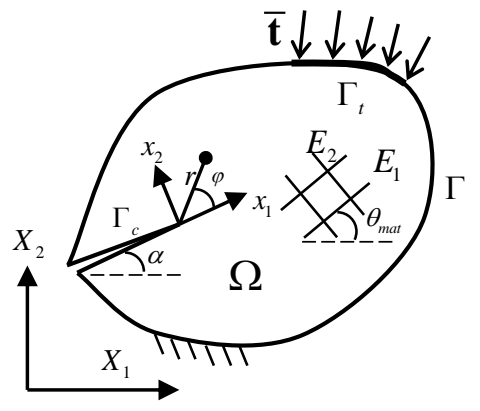

Figure 1. Orthotropic crack model

\subsection{Crack behavior of orthotropic material}

Consider an orthotropic cracked body subjected to arbitrary forces with general boundary conditions as shown in Fig. 1. Global Cartesian coordinates $\left(X_{1}, X_{2}\right)$, local Cartesian coordinates $\left(x_{1}, x_{2}\right)$ and local polar coordinates $(r, \varphi)$ defined on the crack tip are also displayed. Using equilibrium and compatibility conditions [21], a four-order partial differential equation with the following characteristic equation can be obtained

$$
\begin{aligned}
C_{11}^{2 D} s^{4}-2 C_{13}^{2 D}+ & \left(2 C_{12}^{2 D}+C_{33}^{2 D}\right) s^{2} \\
& -2 C_{23}^{2 D} s+C_{22}^{2 D}=0
\end{aligned}
$$

It was proved by Lekhnitskii [21] that the roots $s_{k}$ of Eq. (3) are always complex or purely imaginary $\left(s_{k}=s_{k x}+i s_{k y}, k=1,2\right)$ and occured in conjugate pairs as $s_{1}, \bar{s}_{1}$ and $s_{2}, \bar{s}_{2}$. The displacement and stress fields in the vicinity of the crack tip are given in [1].

\subsection{Criterion for crack growth direction}

In orthotropic material, the crack growth direction is predicted based on the maximum hoop stress criterion [27]. This criterion means that the crack tends to propagate in the direction where the hoop stress $\sigma_{\varphi}$ is maximum. Moreover, diferent from isotropic material that has only one fracture toughness value in every direction, in orthotropic case, the fracture toughness is given by

$$
K_{I C}^{\theta}=K_{I C}^{1} \cos ^{2} \varphi+K_{I C}^{2} \sin ^{2} \varphi
$$

where $K_{I C}^{1}$ and $K_{I C}^{2}$ respectively are the fracture toughness of material along direction 1 and 2 . These values are assumed to relate to the ratio of elastic modulii as below [27] 


$$
\frac{E_{2}}{E_{1}}=\frac{K_{I C}^{1}}{K_{I C}^{2}}
$$

To apply this criterion for crack propagation in orthotropic model that have general crack angle and material orientation, the formulation is generalized as [28]

$$
\frac{\sigma_{\varphi}}{\frac{E_{2}}{E_{1}} \cos ^{2}\left(\varphi-\theta_{\text {mat }}+\alpha\right)+\sin ^{2}\left(\varphi-\theta_{\text {mat }}+\alpha\right)}
$$

where $\theta_{\text {mat }}$ is the material orientation and $\alpha$ is the crack angle. The value of $\varphi$ that makes the expression (6) get maximum is the crack growth direction.

\section{X-MK FORMULATION FOR CRACK PROBLEM.}

\subsection{The moving Kriging shape function}

According to $\mathrm{Gu}$ et al. [22], the approximation of the distribution functions $\mathbf{u}\left(\mathbf{x}_{i}\right)$, within a subdomain $\Omega_{x} \subseteq \Omega$, is interpolated based on all nodal values at $\mathbf{x}_{i}$ within this sub-domain $(i=1, \ldots, n$ and $n$ is the total number of nodes in the sub-domain). The moving Kriging interpolation $u^{h}(\mathbf{x})$, $\forall \mathbf{x} \in \Omega_{x}$ is defined as

$$
\begin{aligned}
u^{h}(\mathbf{x}) & =\left[\mathbf{p}^{\mathrm{T}}(\mathbf{x}) \mathbf{A}+\mathbf{r}^{\mathrm{T}}(\mathbf{x}) \mathbf{B}\right] \mathbf{u}(\mathbf{x}) \\
& =\boldsymbol{\Phi}(\mathbf{x})^{\mathrm{T}} \mathbf{u}(\mathbf{x})
\end{aligned}
$$

where $\mathbf{u}(\mathbf{x})$ is the vector of nodal displacements; $\mathbf{p}(\mathbf{x})$ is the vector of $m$ polynomial basis functions and

$\mathbf{r}(\mathbf{x})=\left[\begin{array}{llll}R\left(\mathbf{x}_{1}, \mathbf{x}\right) & R\left(\mathbf{x}_{2}, \mathbf{x}\right) \quad \ldots & R\left(\mathbf{x}_{n}, \mathbf{x}\right)\end{array}\right]^{\mathrm{T}}$ is the vector of $n$ correlation functions. The vector of basis functions can be chosen as linear functions $\mathbf{p}^{\mathrm{T}}(\mathbf{x})=\left[\begin{array}{lll}1 & x & y\end{array}\right]$.

The matrixes $\mathbf{A}(3 \times n)$ and $\mathbf{B}(\mathrm{n} \times \mathrm{n})$ are determined by $\mathbf{A}=\left(\mathbf{P}^{\mathrm{T}} \mathbf{R}^{-1} \mathbf{P}\right)^{-1} \mathbf{P}^{\mathrm{T}} \mathbf{R}^{-1}$ and $\mathbf{B}=\mathbf{R}^{-1}(\mathbf{I}-\mathbf{P A})$

where $\mathbf{I}$ is an unit matrix, matrix $\mathbf{P}$ of the basis functions and correlation matrix $\mathbf{R}$ are given in detail in [22]

In this study, the Gaussian function is used as correlation function

$$
R\left(\mathbf{x}_{i}, \mathbf{x}_{j}\right)=e^{-\frac{1}{2 l_{c}^{2}} r_{i j}^{2}}
$$

where $l_{c}$ factor can be taken as the average distance between nodes in the domain and $r_{i j}=\left\|\mathbf{x}_{i}-\mathbf{x}_{j}\right\|$. The choise of correlation function as in Eq. (8) is to eliminate the effect of the correlation coeffiction in the Gaussian correlation function in [22].

\subsection{Meshless $X$-MK discretization and vector level set method}

Based on the extrinsic enrichment technique, the displacement approximation $u^{h}$ is rewritten in terms of the signed distance function $f$ and the distance from the crack tip as follow:

$$
\begin{aligned}
& u^{h}(\mathbf{x})=\sum_{I \in W(\mathbf{x})} \phi_{I}(\mathbf{x}) u_{I}+\sum_{I \in W_{b}(\mathbf{x})} \phi_{I}(\mathbf{x}) \alpha_{I} H(f(\mathbf{x})) \\
& +\sum_{I \in W_{S}(\mathbf{x})} \phi_{I}(\mathbf{x}) \sum_{j=1}^{4} B_{j}(\mathbf{x}) \beta_{I j}
\end{aligned}
$$

where $\phi_{I}$ is the moving Kriging shape functions [22] and $f(\mathbf{x})$ is the signed distance from the crack line. The jump enrichment functions $H(f(\mathbf{x}))$ and the vector of branch enrichment functions $B_{j}(j=1,2,3,4)$ are defined respectively by $[10]$

$$
\begin{aligned}
& H(f(\mathbf{x}))=\left\{\begin{array}{lll}
+1 & \text { if } f(\mathbf{x})>0 \\
-1 & \text { if } f(\mathbf{x})<0
\end{array}\right. \\
& B_{j}(\mathbf{x})=\left[\sqrt{r} \cos \frac{\gamma_{1}}{2} \sqrt{g_{1}(\theta)},\right. \\
& \sqrt{r} \cos \frac{\gamma_{2}}{2} \sqrt{g_{2}(\theta)}, \\
& \left.\sqrt{r} \sin \frac{\gamma_{1}}{2} \sqrt{g_{1}(\theta)}, \sqrt{r} \sin \frac{\gamma_{2}}{2} \sqrt{g_{2}(\theta)}\right]
\end{aligned}
$$

where $r$ is the distance from $\mathrm{x}$ to the crack tip $\mathbf{x}_{T I P}$ and $\varphi$ is the angle between the tangent to the crack line and the segment $\mathbf{x}-\mathbf{x}_{T I P}$ as shown in Fig. 2. The functions $\gamma_{j}$ and $g_{j}(j=1,2)$ in Eq. (11) can be written as

$$
\gamma_{j}=\arctan \left(s_{j y} \sin \theta /\left(\cos \theta+s_{j x} \sin \theta\right)\right)
$$




$$
g_{j}(\theta)=\sqrt{\left(\cos \theta+s_{j x} \sin \theta\right)^{2}+\left(s_{j y} \sin \theta\right)^{2}}
$$

In Eq. (9), $W_{b}$ denotes the set of nodes whose support contains the point $\mathrm{x}$ and is bisected by the crack line and $W_{s}$ is the set of nodes whose support contains the point $\mathrm{x}$ and is slit by the crack line and contains the crack tip. $\alpha_{I}, \beta_{l j}$ are additional variables in the variational formulation [18].

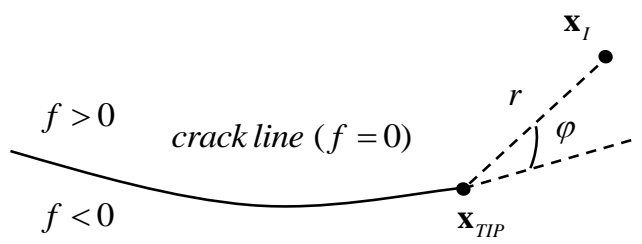

Figure 2. Distance $r$ and angle $\varphi$

\subsection{Discrete equations}

Applying the meshless procedure [23] by substituting the approximation (9) into the wellknown weak form for solid problem, a linear system of equation can be written as

$$
\mathbf{K u}=\mathbf{F}
$$

with $\mathbf{K}$ being the stiffness matrix, respectively, and $\mathbf{F}$ being the vector of force, they can be defined by

$$
\begin{aligned}
& \mathbf{K}_{I J}=\int_{\Omega} \mathbf{B}_{I}^{T} \mathbf{D B} \mathbf{B}_{J} d \Omega \\
& \mathbf{F}_{I}=\int_{\Omega} \boldsymbol{\Phi}_{I}^{T} \mathbf{b}_{I} d \Omega+\int_{\Gamma_{t}} \boldsymbol{\Phi}_{I}^{T} \overline{\mathbf{t}_{l}} d \Gamma
\end{aligned}
$$

where $\boldsymbol{\Phi}$ is the vector of enriched MK shape functions; the displacement gradient matrix B must be calculated appropriately dependent upon enriched or non-enriched nodes [20].

\section{STRESS INTENSITY FACTORS CALCULATION FOR ORTHOTROPIC MODELS.}

The stress intensity factors are important parameters in linear elastic fracture mechanics, they are used to evaluate the status of crack and predict the angle of crack propagation.

In this paper, the interaction integral derived from the path independent $\mathrm{J}$-integral is used to extract the SIFs for orthotropic model [13]. The path independent integration can be written as

$$
I=\int_{A}\left(\sigma_{i j} u_{i, 1}^{a u x}+\sigma_{i j}^{a u x} u_{i, 1}-\sigma_{i j}^{a u x} \varepsilon_{i j} \delta_{1 j}\right) q_{, j} d A
$$

where $\sigma_{i j}, u_{i, 1}$ and $\sigma_{i j}^{a u x}, u_{i, 1}^{a u x}$ are real and auxiliary states of stress and derivative of displacement respectively. The weight function $q$ is defined in [13]

The stress intensity factors can then be evaluated by solving a system of linear algebraic equations:

$$
\begin{aligned}
& I^{(1)}=2 d_{11} K_{I}+d_{12} K_{I I} \\
& I^{(1)}=d_{12} K_{I}+2 d_{22} K_{I I}
\end{aligned}
$$

where

$$
\begin{aligned}
& d_{11}=-\frac{C_{11}}{2} \operatorname{Im}\left(\frac{s_{1}+s_{2}}{s_{1} s_{2}}\right), \\
& d_{12}=-\frac{C_{22}}{2} \operatorname{Im}\left(\frac{1}{s_{1} s_{2}}\right)+\frac{C_{11}}{2} \operatorname{Im}\left(s_{1} s_{2}\right), \\
& d_{22}=\frac{C_{11}}{2} \operatorname{Im}\left(s_{1}+s_{2}\right)
\end{aligned}
$$

\section{NUMERICAL EXAMPLES.}

\subsection{Single mode: Square plate with center crack}

The first example deals with an orthotropic square plate with a center crack, the dimensions are $W=H=20 \mathrm{~mm}$ shown in Fig. 3. The plate are subjected to a uniform tensile stress $\sigma_{0}=1 \mathrm{kN} / \mathrm{mm}^{2}$ at the top and bottom edges. The crack length $2 a=2 \mathrm{~mm}$ and the orthotropic material properties are given as $E_{1}=114.8 G P a$, $E_{2}=11.7 \mathrm{GPa}, v_{12}=0.21$, and $G_{12}=9.66 \mathrm{GPa}$. Due to the symmetry of the model, a uniform nodal distribution of $20 \times 40$ nodes are used for a half of the plate. The dimensionless size of support domain is considered as $\alpha_{s d}=2.0$.

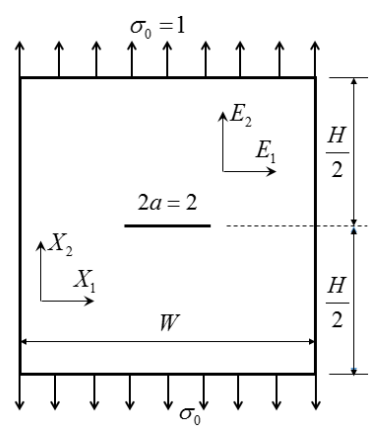

Figure 3. Square orthotropic plate with center crack 
The results for normalized mode-I SIF $\bar{K}_{I}=K / \sigma_{0} \sqrt{\pi a}$ are given in Table 1 . The obtained X-MK results are compared to the solutions given by other methods such as FEM [24], XFEM [12], X-RPIM [20] and EFG [16].

Table 1. Normalize mode-I SIF for square orthotropic plate

\begin{tabular}{lcc}
\hline \multicolumn{1}{c}{ Method } & DOFs & $\bar{K}_{I}$ \\
\hline X-MK (this work) & 3600 & 1.031 \\
X-RPIM [20] & 3600 & 1.022 \\
Conventional EFG [16] & 3875 & 0.965 \\
Modified EFG [16] & 4035 & 1.005 \\
FEM [24] & 11702 & 0.997 \\
XFEM [12] & 4278 & 1.020 \\
\hline
\end{tabular}

In Table 1, the values of DOFs in X-MK and XRPIM are assumed for the full models. Practically, authors only use 800 nodes (1600 dofs) for the symmetric model. The numerical results of the SIFs indicated that the proposed X-MK method gives acceptable solution with fewer DOFs than others.

To investigate the effect of the dimensionless size of support domain, various values of $\alpha_{s d}$ are considered and reported in Table 2. It can be seen that the optimum values for this size coefficient are from 1.9 to 2.1 .

Table 2. Normalized mode-I SIF with different sizes of support domain

\begin{tabular}{cc}
\hline$\alpha_{\text {sd }}$ & $\bar{K}_{I}$ \\
\hline 1.8 & 0.977 \\
1.9 & 1.051 \\
2.0 & 1.031 \\
2.1 & 1.015 \\
2.2 & 0.936 \\
2.3 & 0.921 \\
\hline
\end{tabular}

\subsection{Orthotropic plate with edge crack under shear} stress

In the second example, a cantilever orthotropic plate with an edge crack is considered as shown in Fig. 4. The plate is subjected to a shear stress at the top edge. Dimension, load and boundary condition are display in Fig. 4. The orthotropic material properties are $E_{1}=114.8 G P a, E_{2}=11.7 G P a$, $v_{12}=0.21$ and $G_{12}=9.66 \mathrm{GPa}$. Various cases of orthotropic material axes are considered $\left(\alpha=-90^{\circ} \div 90^{\circ}\right)$. A distribution of $20 \times 40$ scatter nodes is used in this plane stress analysis.

Mixed-mode normalized stress intensity factors versus orthotropy angles are plotted in Fig. 5. The obtained results are compared to solutions given by X-RPIM [25], EFG [16] and FEM [26]. The charts show a very good agreement acquired between solutions.

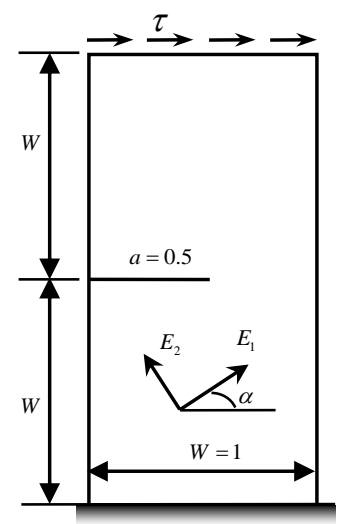

Figure 4. Orthotropic edge crack plate under shear loading

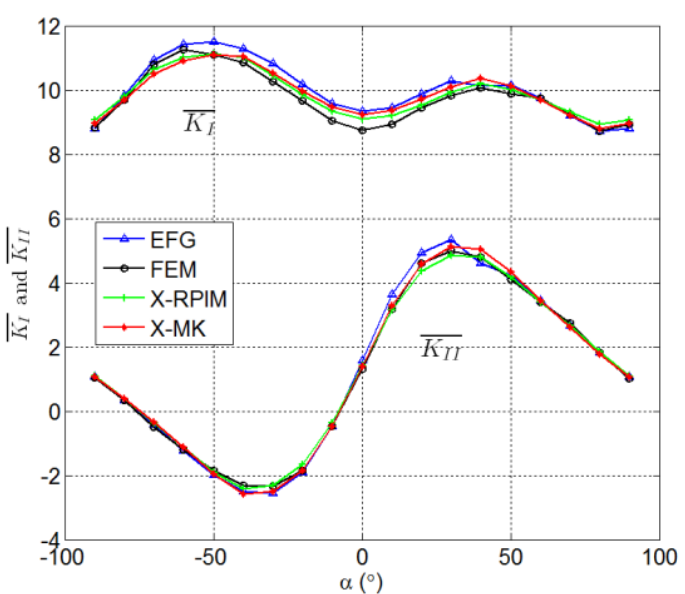

Figure 5. Normalized SIFs results with several orientations of the axes of orthotropy

\subsection{Predicting for propagation angle}

In this example, a rectangular speciment with an edge crack is subjected to a uniform tensile loading at both top and bottom edges. The orthotropic material properties are $E_{1}=139 G P a, E_{2}=10 G P a$, $G_{12}=5.2 \mathrm{GPa}$ and $v_{12}=0.3$. The configuration is plotted in Fig. 6 and all dimensions are given in $\mathrm{mm}$. 


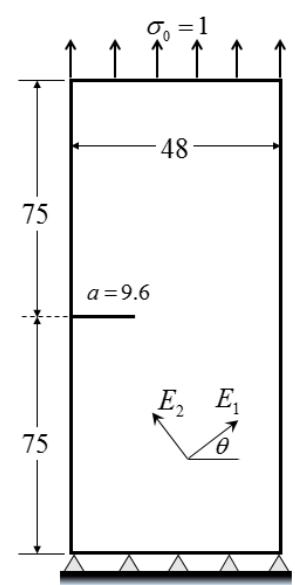

Figure 6. Normalized SIFs results with several orientations

A distribution of $20 \times 50$ scatter nodes and the size of crack increment $\Delta a=3$ are used for this simulation. The predicted initial propagation angles with respect to the material orientation angles are shown in Table 3. The obtained results match well with solution from experiment and XFEM [28]. To investigate the effect of material orientation angle on the crack path, various cases of $\theta$ are considered. Charts in Fig. 7 shows crack paths with $\theta=0^{\circ}, 30^{\circ}, 45^{\circ}, 60^{\circ}$ and $90^{\circ}$. These crack paths can be compared directly to experimental results given in [28].

Table 3. Initial crack propagation angles (degree)

\begin{tabular}{|c|c|c|c|}
\hline$\theta\left({ }^{0}\right)$ & X-MK & Experimental & X-FEM \\
\hline 0 & 0.91 & 0 & 0 \\
\hline 30 & 30.00 & 30 & 29 \\
\hline 45 & 42.73 & 45 & 43 \\
\hline 60 & 57.27 & 60 & 57 \\
\hline 90 & 82.73 & 90 & 83 \\
\hline
\end{tabular}

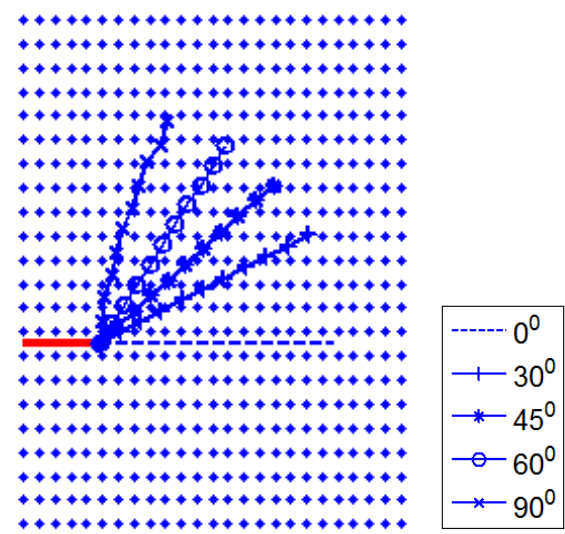

Figure 7. Crack paths with various values of angle $\theta$

\section{CONSLUSION}

An extended meshless method based on moving Kriging interpolation (X-MK) has been proposed for cracks analysis in orthotropic with several material orientations. The MK shape functions satisfy the Kronecker's delta property so the Dirichlet boundary conditions can be enforced conveniently. Several numerical examples including SIFs calculation and crack growth simulation are considered with different material models and loading conditions. A good agreement between the proposed method and the references. The presented $\mathrm{X}-\mathrm{MK}$ is promising to be extended to more complex problems such as dynamic SIFs calculation and dynamic crack propagation problems of orthotropic materials.

\section{REFERENCES}

[1] Sih GC, Paris PC, Irwin GR. On cracks in rectilinearly anisotropic bodies. Int J Fract Mech 1965;1:189-203.

[2] Bowie OL, Freese CE. Central crack in plane orthotropic rectangular sheet. Int J Fract Mech 1972;8:49-58.

[3] Tupholme G. E. A study of cracks in orthotropic crystals using dislocations layers, J. Eng. Math. 1974; 8, 57-69.

[4] Barnett DM, Asaro RJ. The fracture mechanics of slit-like cracks in anisotropic elastic media. J Mech Phys Solids 1972; 20:353-66.

[5] Kuo MC, Bogy DB. Plane solutions for the displacement and traction-displacement problem for anisotropic elastic wedges. J Appl. Mech 1974; 41:197-203

[6] Nobile L, Carloni C. Fracture analysis for orthotropic cracked platest. Comp Struct 2005; 68(3), 285-93.

[7] Nobile L, Piva A, Viola E. On the inclined crack problem in an orthotropic medium under biaxial loading. Eng Fract Mech 2004; 71, 529-46.

[8] Carloni C, Nobile L. Crack initiation behaviour of orthotropic solids as predicted by the strain energy density theory. Theoret Appl Fract Mech 2002; 38, 109-19.

[9] Carloni C, Piva A, Viola E. An alternative complex variable formulation for an inclined crack in an orthotropic medium. Eng Fract Mech 2003; 70, 2033-58

[10] A. Asadpoure, S. Mohammadi, A. Vafait. Crack analysis in orthotropic media using the extended finite element method. Thin-Walled Structures 2006; 44, 1031-1038. 
[11] A. Asadpourea, S. Mohammadi, A. Vafait. Modeling crack in orthotropic media using a coupled finite element and partition of unity methods. Finite Elements in Analysis and Design 2006; 42; 1165 - 1175.

[12] A. Asadpoure, S. Mohammadi. Developing new enrichment functions for crack simulation in orthotropic media by the extended finite element method. Int. J. Numer. Meth. Engng 2007; 69, 2150-2172.

[13] D. Motamedi, S. Mohammadi. Dynamic crack propagation analysis of orthotropic media by the extended finite element method. Int J Fract 2010; 161, 21-39.

[14] Aliabadi MH, Sollero P. Crack growth analysis in homogeneous orthotropic laminates. Comp Sci Technol 1998; 58, 1697-703.

[15] T. Belytschko, Y.Y. Lu, L. Gu. Element-free Galerkin methods, Int. J. Numer. Meth. Eng. 1994; 37, 229-256.

[16] S. S. Ghorashi, S. Mohammadi, Saeed-Reza SabbaghYazdi. Orthotropic enriched element free Galerkin method for fracture analysis of composites. Engineering Fracture Mechanics 2011; 78, 1906-1927.

[17] M. Fleming, Y. A. Chu, T. Belytschko. Enriched ElementFree Galerkin methods for crack tip fields, International Journal for Numerical Methods in Engineering 1997; 40, 1483-1504.

[18] G. Ventura et al. A vector level set method and new discontinuity approximations for crack growth by EFG, International Journal for Numerical Methods in Engineering 2002; 54, 923-944.

[19] P.H. Wen and M.H. Alibadi. Evaluation of mixed-mode stress intensity factors by the mesh-free Galerkin method: Static and dynamic. The Journal of Strain Analysis for Engineering Design 2009, 44, 273-286.

[20] Nguyen T.N., Bui T.Q., Zhang Ch., Truong T.T.. Crack growth modeling in elastic solids by the extended meshfree Galerkin radial point interpolation method. Engineering Analysis with Boundary Elements 2014; 44, 87-97.

[21] Lekhnitskii SG. Theory of an anisotropic elastic body. San Francisco: Holden-Day; 1963.

[22] L. Gu, "Moving kriging interpolation and element-free Galerkin method" International Journal for Numerical Methods in Engineering, vol. 56, pp. 1-11, 2003

[23] Liu G. R. - Mesh Free Methods. Moving beyon the Finite Element Method. CRC Press LLC (2003).

[24] Kim, J. H., \& Paulino, G. H. (2003). The interaction integral for fracture of orthotropic functionally graded materials: evaluation of stress intensity factors. International Journal of Solids and Structures, 40(15), pp. 3967-4001.

[25] Nguyen T.N., Bui T.Q., Truong T.T.. Extended Radial Point Interpolation Method for crack analysis in orthotropic media. Science and Technology Development 2015; 15(K4), 5-13.

[26] Chu S. J., Hong C. S. Application of the integral to mixed mode crack problems for anisotropic composite laminates. Engng Fract Mech 1990; 35(6), 1093-103.

[27] Saouma VE, Ayari ML, Leavell DA. Mixed mode crack propagation in homogenous anisotropic solids. Eng Fract Mech 1987: 27(2s) 171-184.

[28] Cahill L.H.A., Natarajan S., Bordas S.P.A., O'Higgins R.M., McCarthy C. T. An experimental/numerical investigation into the main driving force for crack propagation in uni-directional fibre-reinforced composite laminae. Composite Structures 2014, 107, 119-130 .

Nguyen, N. Minh received the B.E. degree (2008) in Engineering Mechanics from Ho Chi Minh city University of Technology, VNU-HCM Viet Nam, and M.E. degree (2011) in Computational Engineering from Ruhr University Bochum, Germany.

$\mathrm{He}$ is a Lecturer, Department of Engineering Mechanics, Ho Chi Minh City University of Technology, VNU-HCM. His current interests include heat transfer analysis, fracture analysis and numerical methods.

Nguyen, Thanh Nha received the B.E. (2007) and M.E. (2011) degrees in Engineering Mechanics from Ho Chi Minh city University of Technology, VNU-HCM.

$\mathrm{He}$ is a Lecturer, Department of Engineering Mechanics, Ho Chi Minh City University of Technology, VNU-HCM. His current interests include fracture analysis in composite materials and numerical methods.

Bui, Quoc Tinh received his Bachelor degree (2002) in Mathematics from University of Science, VNU-HCM, Ho Chi Minh city, Viet Nam; M. E degree (2006) from University of Liege, Belgium and $\mathrm{PhD}$ degree (2009) from Technical University of Vienna, Austria.

$\mathrm{He}$ is an Associate Professor, Department of Civil and Environmental Engineering, Tokyo Institute of Technology, Japan. His current interests include fracture analysis, damage analysis and numerical methods.

Truong, Tich Thien received his B.E. (1986) and M.E. (1992) and $\mathrm{PhD}$ degrees in Mechanical 
Engineering from Ho Chi Minh city University of Technology, VNU-HCM.

$\mathrm{He}$ is an Associate Professor, Department of Engineering Mechanics, Ho Chi Minh City University of Technology, VNU-HCM. His current interests include fracture analysis and numerical methods.

\title{
Phương pháp không lưới moving Kriging mở rộng cho phân tích lan truyền vết nứt trong vật liệu trực hướng
}

\author{
Nguyễn Thanh Nhã ${ }^{1}$, Nguyễn Ngọc Minh ${ }^{1}$, Bùi Quốc Tính², Trương Tích Thiện ${ }^{1, *}$ \\ ${ }^{1}$ Trường Đại học Bách Khoa, ĐHQG-HCM \\ ${ }^{2}$ Viện Công nghệ Tokyo, Nhật Bản \\ Tác giả liên hệ: tttruong@hcmut.edu.vn
}

Ngày nhận bản thảo: 12-6-2017, ngày chấp nhận đăng: 18-11-2017

Tóm tắt—Vật liệu composite trực hướng là một dạng đặc biệt trong nhóm vật liệu bất đẳng hướng và các sản phẩm từ vật liệu này ngày càng được sử dụng rộng rãi trong kỹ thuật. Việc nghiên cứu ứng xử cơ học của loại vật liệu này là rất cần thiết. Trong nghiên cứu này, tác giả áp dụng phương pháp không lưới mở rộng dựa trên phép nội suy moving Kriging (X-MK) cho bài toán phân tích nứt trong vật liệu composite trực hướng. Hàm Gauss được dùng để thiết lập hàm dạng moving Kriging. Uuu điểm của hàm dạng MK là thỏa mãn thuộc tính Kronecker's delta và liên tục bậc cao. Để tính toán hệ số cường độ ứng suất (SIFs), phương pháp tích phân tương tác được sử dụng kết hợp với miền phụ trọ̣ trực hướng lân cận đỉnh vết nứt. Các ví dụ số được thực hiện bao gồm các bài tính hệ số SIFs và dự đoán hướng lan truyền vết nứt nhằm kiểm chứng sự chính xác của phương pháp. Các kết quả thu được được so sánh với các lời giải tham khảo từ các phương pháp khác và sự phù hợp giữa các kết quả thể hiện tính đúng đắn của phương pháp đối với bài toán đã đề cập.

Tù khóa—vật liệu trực hướng, cơ học phá hủy, hệ số cường độ ứng suất, phương pháp không lưới MK. 